\title{
ARTIGOS
}

\section{CURRÍCULO DO PRÉ-SECUNDÁRIO EM TIMOR-LESTE E SUA ARTICULAÇ̃̃O COM O SECUNDÁRIO GERAL}

\author{
ANA MARGARIDA CAPELO • ISABEL CABRITA
}

\section{RESUMO}

Problemas herdados nas últimas décadas conduziram Timor-Leste a reestruturar os currículos do ensino pré-secundário - EPS - e do secundário geral - ESG. ${ }^{1}$ Atendendo à importância de uma adequada articulação vertical ao longo dos ciclos de escolaridade e diante do cumprimento de uma primeira edição completa do EPS, importa estudar se tal currículo está alinhado com o do ESG, em particular no que respeita às Ciências e Tecnologia. Este artigo centra-se na análise do currículo do EPS e na avaliação da sua articulação com o do ESG. Não obstante existam décalages entre o currículo prescrito, o implementado e o apropriado, é relevante haver sintonia no nível dos currículos para uma educação e formação de boa qualidade, fundamentais à consecução dos Objetivos de Desenvolvimento do Milénio.

CURRÍCULO • ENSINO SECUNDÁRIO • POLÍTICAS EDUCACIONAIS • TIMOR-LESTE

\section{MIDDLE SCHOOL CURRICULUM IN EAST-TIMOR AND ITS ARTICULATION WITH SECONDARY SCHOOL}

\section{ABSTRACT}

Problems inherited from the last decades have led Timor-Leste to restructure its pre-secondary - EPS - and general secondary - ESG - curricula. Considering the importance of an adequate vertical articulation throughout the schooling cycles and before the conclusion of the first complete edition of the EPS, it is necessary to study if such a curriculum is aligned with the one of the ESG, in particular with regard to Science and Technology. This article focuses on the analysis of the EPS curriculum and the evaluation of its articulation with the one of ESG. Notwithstanding the décalages among the prescribed, the implemented and the appropriate curricula, it is relevant to have a fine-tuning at this level to ensure good quality education and training, essential to achieve the millennium development goals. 


\section{PROGRAMME D'ENSEIGNEMENT PRÉSECONDAIRE AU TIMOR-ORIENTAL ET SON ARTICULATION AVEC L'ENSEIGNEMENT SECONDAIRE \\ RÉSUMÉ}

Des problèmes hérités des dernières décennies ont conduit le Timor-Oriental à restructurer ses programmes d'enseignement présecondaire - EPS -, ainsi que ceux de l'enseignement secondaire général - ESG. Compte tenu de l'importance d'une bonne articulation verticale tout au long des cycles scolaires etvu qu'une première édition complète de l'EPS a déjà été mise en place, il est important de vérifier si ce programme s'aligne bien à celui de l'ESG, particulièrement en ce qui concerne les Sciences et la Technologie. Cet article se concentre sur l'analyse du programme de l'EPS et sur l'évaluation de son articulation avec celui de l'ESG. Nonobstant certains décalages entre le programme prescrit, celui qui a été mis en ouvre et celui qui est approprié, il est nécessaire que les programmes soient en phase pour atteindre une éducation et une formation de qualité, fondamentales pour la réalisation des Objectifs du Millénaire pour le Développement.

CURRICULUM • ENSEIGNEMENT SECONDAIRE • POLITIQUE D'ÉDUCATION •

TIMOR-LESTE

\section{CURRÍCULO DE LA PRE SECUNDARIA EN TIMOR ORIENTAL Y SU ARTICULACIÓN CON LA SECUNDARIA GENERAL}

RESUMEN

Problemas heredados en las últimas décadas hicieron que Timor Oriental reestructurase los currículos de la educación pre secundaria - EPS - y de la secundaria general - ESG. En función de la importancia de una adecuada articulación vertical a lo largo de los ciclos de escolaridad y frente al cumplimiento de una primera edición completa do EPS, importa estudiar si tal currículo está alineado con el del ESG, en particular en lo que concierne a las Ciencias y Tecnología. Este artículo se centra en el análisis del currículo del EPS y en la evaluación de su articulación con el del ESG. No obstante la existencia de décalages entre el currículo prescrito, el implementado y el apropiado, es relevante que haya sintonía a nivel de los currículos para una educación y formación de calidad, fundamentales para la consecución de los Objetivos de Desarrollo del Milenio. 
NÚMEROS ESTUDOS NO ÂMBITO DE REFORMAS EDUCATIVAS EM PAÍSES EM DESENVOLVIMENTO (MUNAVU; OGUTU; WASANGA, 2008) evidenciam que a revisão e/ou reformulação frequente dos currículos se sucedem para adequar o sistema educativo aos desígnios nacionais. Entre esses desígnios, destaca-se a necessidade de maximizar os recursos alocados ao setor da educação, acompanhar a evolução de outros países e dar resposta aos avanços tecnológicos, cumprir as exigências de construir novos conhecimentos e possibilitar que os alunos atinjam níveis de desempenho mais desejáveis (MUNAVU; OGUTU; WASANGA, 2008). No caso de países que passaram por situações de guerra e conflitos, a importância de reformas educativas é reforçada, em prol da sua reconstrução.

Timor-Leste não é exceção e planos do governo, como o documento Política Nacional da Educação e Cultura 2006-2010, expressam a necessidade de o país desenvolver "um sistema educativo, unificado e flexível capaz de responder à realidade nacional, de modo a permitir que todo o cidadão obtenha um espaço de desenvolvimento de acordo com a sua vontade e capacidade" (TIMOR-LESTE, 2006). ${ }^{2}$ Tendo em vista que um em cada três alunos timorenses está, ainda, no ensino pré-secundário - EPS -, apesar de ter, oficialmente, idade para frequentar o ensino secundário - ES - (UNITED NATIONS EDUCATIONAL, SCIENTIFIC AND CULTURAL ORGANIZATION - UNESCO, 2012), atenção particular tem sido dada à melhoria e expansão de todo o sistema de ensino (TIMOR-LESTE, 2011a). Nesse contexto, o governo de Timor-Leste, por via da cooperação internacional, implementou sérias reformas no sistema educativo, a começar pela restruturação do currículo do ensino primário - EP - (SHAH, 2012), seguindo-se 
a do EPS (PACHECO et al., 2009) e, finalmente, a do ensino secundário geral - ESG. ${ }^{3}$ Simultaneamente, o governo tem vindo a intervir em outras áreas-chave, nomeadamente, ao nível:

- macro - na (re)formulação de políticas educativas administrativas e legislativas;

- meso - em alterações nas infraestruturas logísticas, organizacionais e de apoio à formação de professores;

- micro - na criação de condições para a formação de professores, de acordo com os novos currículos, e na elaboração de diretrizes no âmbito da articulação vertical entre os currículos (TIMOR-LESTE, 2011b).

Explorar a articulação entre os currículos dos ensinos pré-secundário e secundário geral em Timor-Leste constitui o objetivo da presente comunicação, cuja secção principal se organiza em torno de quatro pontos:

- articulação vertical entre currículos de níveis educativos consecutivos;

- descrição do contexto de restruturação curricular do EPS e ESG em Timor-Leste;

- caraterização do currículo do EPS timorense;

- $\quad$ articulação entre os currículos do EPS e do ESG daquele país.

\section{ARTICULAÇÃO ENTRE OS CURRÍCULOS DOS ENSINOS PRÉ-SECUNDÁRIO E SECUNDÁRIO GERAL EM TIMOR-LESTE}

Enquadrada por uma sintética revisão de literatura sobre a questão da articulação vertical dos curricula, nesta parte, tendo como contexto particular a restruturação do sistema educativo em Timor-Leste, analisa-se o currículo timorense do ensino pré-secundário ao nível de seus princípios, finalidades, objetivos, conteúdos, orientações metodológicas e práticas avaliativas e reflete-se sobre a sua articulação com o currículo do ensino secundário geral.

\section{ARTICULAÇÃO VERTICAL ENTRE CURRÍCULOS DE NÍVEIS EDUCATIVOS CONSECUTIVOS}

Em muitos países, a reformulação ou restruturação do currículo é cada vez mais vista como a base de muitas reformas educativas, que são implementadas com o intuito primeiro de se alcançarem melhores resultados ao nível da aprendizagem dos alunos, possibilitando a melhoria de toda a situação local, numa lógica global.

O currículo é um assunto estudado, analisado, interpretado, debatido e discutido em múltiplos contextos, mas, principalmente, em ambientes de formação e investigação em educação, designadamente 
em ciências. Sendo um conceito complexo pela sua natureza polissémica, a sua interpretação e análise são muitas vezes imbuídas de subjetividade, dadas as inter-relações e/ou imiscuidade entre, nomeadamente, os significados e papéis que se atribuem ao currículo formal, que corresponde às atividades desenvolvidas na aula, ao currículo informal, que diz respeito às atividades extracurriculares, e ao currículo oculto, traduzido num conjunto de práticas educativas e processos pedagógicos que veiculam aprendizagens que vão para além das consignadas no currículo formal e abrangem, por exemplo, a aquisição de valores e a socialização (FONTOURA, 2000). Por esse motivo, Ferreira (2001) menciona o facto de se poder obter respostas diferentes quando se questiona o que é o currículo, tendo em mente o currículo (formal) prescrito, o efetivamente implementado em aula, o informal ou o oculto. Essas respostas diferentes podem resultar também do facto de o currículo englobar e ser enriquecido pelas relações que se estabelecem entre a matriz curricular definida a nível nacional e os projetos curriculares de escola, entre os currículos de anos anteriores e posteriores (articulação vertical) e entre áreas disciplinares ou dentro da mesma área (articulação horizontal inter ou intradisciplinar) (NDEBELE et al., 2013).

Nesta comunicação, o foco serão o currículo formal prescrito e a articulação vertical, entendida como continuidade dos curricula interciclos (BARBOSA, 2010) e não tanto entre as culturas de escola e os professores (MULLER, 2006).

Assume-se a articulação vertical numa perspetiva de sequencialidade, em espiral, dos currículos, numa lógica de coerência entre todas as dimensões e programas que os integram (ALARCÃO, 2009; GIMENO SACRISTÁN, 1996; RIBEIRO, 2002; ROLDÃO, 2009; STABBACK; MALE; GEORGESCU, 2011; SERRA, 2004), que possibilite acomodar necessidades emergentes de conhecimento e de capacidades, numa perspetiva de aprendizagem ao longo da vida (e.g. BARBOSA, 2010).

\section{A RESTRUTURAÇÃO CURRICULAR DOS ENSINOS PRÉ-SECUNDÁRIO E SECUNDÁRIO GERAL EM TIMOR-LESTE}

Desde há uma década que o governo de Timor-Leste reconheceu a necessidade de implementar alterações profundas a nível do sistema educativo, designadamente, reformular os currículos do EP, EPS e ESG, por via da cooperação internacional, visando a capacitar os cidadãos para enfrentar os desafios do futuro e a contribuir para os Objetivos de Desenvolvimento do Milénio (TIMOR-LESTE, 2011a).

Com base nestes propósitos, entre 2003 e 2009, o governo desenvolveu esforços para a restruturação do currículo do ensino primário (SHAH, 2012). Simultaneamente, com o apoio da United Nations Children's Fund - Unicef - e do Banco Mundial, foram produzidos materiais de apoio e kits para desenvolvimento de atividades práticas de ciências (GABRIELSON; SOARES; XIMENES, 2010). 
Seguiu-se, em 2009, a restruturação do currículo do EPS, que tem na sua base um contrato de cooperação entre a Universidade do Minho e a Unicef, ${ }^{4}$ do qual resultou a produção do Plano curricular do $3^{\circ}$ ciclo do ensino básico e estratégia de implementação. Esse documento visa a nortear a elaboração de futuros programas curriculares, manuais do aluno, eventualmente, e guias do professor e orientar as práticas letivas (PACHECO et al., 2009). Em 2012 ocorreu a implementação desse currículo e, simultaneamente, foi realizado um curso de formação contínua de professores para o ensino básico, também com o apoio da Universidade do Minho (UNITED NATIONS CHILDREN'S FUND - UNICEF, 2010). Foram ainda distribuídos materiais de apoio ao novo currículo, fruto da cooperação portuguesa, brasileira e da Unicef (GABRIELSON; SOARES; XIMENES, 2010). Dados recentes (TIMOR-LESTE, 2015) evidenciam já algumas melhorias em termos de participação dos alunos e de qualidade na educação em Timor-Leste, relativamente aos anos anteriores. No entanto, os mesmos dados revelam que a taxa de matrícula líquida no EPS ainda é de 34\% e que a maioria dos alunos, apesar de ter idade para aceder a esse nível de estudos, não o concretiza (CAPELO; CABRITA, 2015). Tais resultados são agravados por um rápido crescimento populacional, conduzindo a que mais da metade da população tenha menos de 18 anos (ME-RDTL, 2011b).

No que respeita ao ESG, também em 2009, o Ministério da Educação de Timor-Leste, em colaboração com a Universidade de Aveiro, implementou o projeto Falar Português, ${ }^{5}$ do qual resultou a produção dos novos materiais curriculares - plano curricular, programas das disciplinas, manuais do aluno e guias do professor. A implementação desses materiais ocorreu, pela primeira vez, tal como o novo currículo do EPS, em 2012 (CAPELO; CABRITA, 2015). Paralelamente e também em colaboração com a Universidade de Aveiro, o Ministério da Educação implementou o Projeto de Formação Inicial e Contínua de Professores - PFICP (INSTITUTO NACIONAL DE FORMAÇÃO DE DOCENTES E PROFISSIONAIS DA EDUCAÇÃO - INFORDEPE, 2014), para o ESG e o ensino secundário técnico vocacional - ESTV -, orientado por professores portugueses, e que terminou no final de 2014 (CAPELO; CABRITA, 2015). Dados recentes (TIMOR-LESTE, 2015) evidenciam que, em Timor-Leste, a taxa de matrícula líquida, quer no ESG quer no ESTV, ainda é de 25\% (CAPELO; CABRITA, 2015). Outros dados, particularmente os resultantes do projeto (já concluído) de Avaliação do impacte da reestruturação curricular do ensino secundário em Timor-Leste - um estudo no âmbito da cooperação internacional, ${ }^{6}$ relativo à primeira edição da implementação do novo currículo do ESG em Timor-Leste, ${ }^{7}$ mostram que algumas conquistas já foram alcançadas, mas ainda há muitos obstáculos a superar (CABRITA et al., 2015).

Em 2015, iniciou-se uma segunda edição do ESG, com o ingresso de alunos que já cumpriram o novo currículo do EPS. Apesar das décalages entre o currículo prescrito ou enunciado, o currículo implementado e

4

Projecto de

Desenvolvimento do Currículo do $3^{\circ}$ Ciclo da Educação Básica em Timor-Leste (CEB3-TL) - [Agreement UNICEF/ Universidade do Minho SSA/ IDSM/2009/00000315O] (UNICEF, 2010).

\section{5}

Disponível em: <http:// www.ua.pt/esgtimor/ Default.aspx>. Acesso em: 20 dez. 2015.

\section{6}

Este estudo assentou no crescente interesse na Avaliação do Impacte - Al - junto dos países menos desenvolvidos, nomeadamente como consequência natural do investimento na assistência ao desenvolvimento e nos programas de cooperação concretizados por agências internacionais e países parceiros (BAKER, 2000).

7

Disponível em:

<http://projetotimor. web.ua.pt/?page_ $i d=105 \&$ lang $=p t>$. Acesso em: 20 dez. 2015. 
o currículo adquirido, tais alunos possuirão um background diferente daqueles que entraram em 2012, sendo expectável que estejam mais bem preparados para fazer face ao novo currículo do ESG.

Nesse contexto, segue-se uma análise do currículo do EPS a nível dos princípios, finalidades, objetivos, conteúdos, orientações metodológicas e práticas avaliativas que são priorizados.

\section{CARATERIZAÇÃO DO CURRÍCULO DO ENSINO PRÉ-SECUNDÁRIO}

No quadro da Lei de Bases da Educação de Timor-Leste (ponto 1, $\operatorname{art}^{0} 11^{\circ}$ da Lei de Bases da Educação $\left.{ }^{8}\right)$, os primeiros nove anos de escolaridade compreendem o ensino básico, que corresponde ao ensino obrigatório e gratuito. Esse nível de escolaridade inclui o ensino primário, também designado de $1^{\circ}$ ciclo (primeiros quatro anos), o $2^{\circ}$ ciclo (dois anos seguintes) e o $3^{\circ}$ ciclo ou EPS (três últimos anos de escolaridade obrigatória). ${ }^{9}$

Como mencionado anteriormente, o $3^{\circ}$ ciclo do ensino básico passou por uma restruturação curricular (UNICEF, 2008), no âmbito da qual foi criado o Plano curricular do $3^{\circ}$ ciclo do ensino básico e estratégia de implementação (PACHECO et al., 2009). Em traços gerais, tal documento engloba e descreve um quadro de referência teórico de suporte à reforma, bem como explicita as orientações para o desenho e a implementação do currículo (PACHECO et al., 2009). Encontrando-se organizado em torno de um conjunto de seções, o documento aborda, pela seguinte ordem: as linhas orientadoras da reforma curricular em Timor-Leste; fases e contextos de decisão curricular; diferentes formas que o currículo, enquanto projeto, assume ao longo desse percurso, ou seja, o currículo como projeto nacional, como projeto da escola, da comunidade e da sala de aula; prioridades na implementação dessa reforma curricular; e, por último, orientações para o desenvolvimento e monitorização da reforma curricular. Não sendo intenção abordar aqui todas essas dimensões, serão exploradas apenas aquelas que se julgam mais relevantes à luz dos objetivos da presente comunicação.

Tendo em atenção o quadro de referência teórico de suporte à

reforma, esse plano norteia-se pelos princípios e propósitos expressos

\section{[...] na Constituição da República Democrática de Timor-Leste, na Lei de Bases da Educação - Lei n. 14/2008, de 29 de Outubro -, no documento Política Nacional da Educação 2007-2012 e em ou- tros documentos de política curricular, produzidos no âmbito do Ministério da Educação. (PACHECO et al., 2009, p. 5)}

Enquadrado por esses documentos de referência do governo, o referido plano primeiro apresenta os princípios contextualizadores da reforma curricular do ensino básico, comuns aos nove anos de escolaridade obrigatória, e, em seguida, aqueles específicos para o $3^{\circ}$ ciclo do ensino básico. Entre tais princípios contextualizadores, o plano releva, designadamente, que 
a. O currículo nacional deve tornar claro o que os professores devem ensinar, bem como o que os alunos devem aprender, tendo expressão em orientações comuns a todas as escolas, com vista a salvaguardar os princípios da globalização e da sequencialidade curriculares.

b. O currículo nacional terá como eixo estruturante a ideia de que a escola providencia os apoios necessários para que todos os alunos possam concretizar as aprendizagens previstas para as várias áreas e disciplinas.

c. O currículo nacional incidirá em aprendizagens estruturantes que permitam a aquisição e o desenvolvimento quer de uma formação geral, quer de uma formação orientada para o prosseguimento de estudos ou para o acesso ao mercado de trabalho.

d. O currículo nacional abrangerá uma formação de base disciplinar e áreas de formação não disciplinar definidas em função do mandato específico da escola em Timor-Leste.

e. O currículo nacional concretizar-se-á em cada escola tendo em conta os contextos locais e os recursos que professores e alunos podem utilizar para a construção de ambientes de aprendizagem.

f. O currículo nacional estruturar-se-á na observação de uma dimensão comum a todas as escolas, não excluindo a participação das famílias nos contextos escolares, nem ignorando a identidade cultural da comunidade educativa.

g. O currículo nacional será implementado na base da articulação dos órgãos do Ministério da Educação com as estruturas existentes ao nível dos distritos e das escolas.

h. O currículo nacional expressar-se-á na definição de uma cultura básica e comum que compreende um conjunto específico de saberes, valores, atitudes, procedimentos e capacidades, que se adquire através dos processos de ensino e de aprendizagem que têm lugar nas escolas.

i. O currículo nacional basear-se-á na existência de documentos de orientação e de apoio que contribuam para a concretização dos objectivos da educação básica. (PACHECO et al., 2009, p. 20-22)

Entre os princípios fundamentais da proposta de reforma curricular especificamente para o $3^{\circ}$ ciclo do ensino básico, o plano releva, designadamente, o valor de uma educação que contribua para a formação dos alunos timorenses em resposta "a problemas e desafios sociais, económicos e culturais contemporâneos” (PACHECO et al., 2009, p. 22). Reconhece também o ensino básico como 
[...] percurso de escolarização que, em articulação com outros percursos, [assegure] [...] uma formação cultural, ética, cívica e vocacional às crianças e jovens timorenses, [e a de um] [...] currículo nacional como formação de base comum, organizada em função de saberes, valores, atitudes, capacidades e procedimentos necessários para uma efetiva integração e participação sociais. (PACHECO et al., 2009, p. 23)

Assume que a formação de base deve englobar

[...] saberes específicos, ao nível de áreas e disciplinas, e saberes mais gerais, que explorem a compreensão intercultural, o desenvolvimento de competências sociais e a partilha de atitudes de responsabilização pessoal e social [...] [incluindo a] valorização de perspectivas transdisciplinares relacionadas com o contexto específico de Timor-Leste, que valorizem o desenvolvimento sustentável, a educação para a cidadania e a integração de Timor-Leste no espaço asiático. (PACHECO et al., 2009, p. 23)

Advoga, também, que um novo currículo do ensino básico para Timor-Leste deve ser desenvolvido por meio da adoção de metodologias que valorizem

[...] a abordagem participativa, reconhecendo o contributo dos actores educativos timorenses na concepção e implementação das propostas curriculares [...] [e que deve reforçar a] ligação entre a escola, a família e a comunidade, a inclusão de crianças e adolescentes com necessidades educativas especiais e a prevenção do insucesso, abandono ou absentismo escolar. (PACHECO et al., 2009, p. 23)

O plano defende, ainda, que o novo currículo estimule práticas promotoras da liberdade de expressão, o pensamento crítico e uma educação de todos e para todos e que se oriente "para a formação de cidadãos empenhados na manutenção da paz e da estabilidade social, no desenvolvimento e consolidação da democracia e no progresso do país" (PACHECO et al., 2009, p. 23). Por último, defende a monitorização e o acompanhamento das aprendizagens para a promoção da sua qualidade e "uma cultura educativa baseada em formas participadas de avaliação, do recurso a práticas de transparência e prestação de contas e da apropriação comunitária da escola” (PACHECO et al., 2009, p. 24).

No que diz respeito aos princípios curriculares que devem nortear as decisões no próprio contexto de realização, o documento valoriza: a adaptação curricular numa perspetiva de os processos de ensino 
e aprendizagem se adaptarem aos alunos; a diferenciação da aprendizagem de forma a proporcionar diferentes caminhos de aprendizagem e cada um conseguir alcançar o sucesso educativo; e a valorização da aprendizagem de modo a motivar e responsabilizar os alunos pelo seu sucesso educativo (PACHECO et al., 2009).

Uma vez destacadas as intenções do governo, ou seja, os princípios do sistema educativo - tais como os contextualizadores da reforma do ensino básico, também designados de linhas de força do currículo nacional; os que fundamentam a proposta de reforma curricular do ensino básico, em geral, e do $3^{\circ}$ ciclo, em particular; e os curriculares que devem nortear as decisões no próprio contexto de realização -, o documento salienta que no processo de prescrição curricular ${ }^{10}$ se deve atender a um conjunto de aspetos, nomeadamente: realização pessoal e comunitária do indivíduo; ensino para todos; democratização do ensino; e um ensino geral “evitando as escolhas prematuras” (PACHECO et al., 2009, p. 34).

Já como princípios organizadores do currículo do $3^{\circ}$ ciclo do ensino básico, também denominado de EPS, o plano destaca que o currículo deve ser abrangente, articulado numa perspetiva de "sequência vertical e organização horizontal dos saberes” (PACHECO et al., 2009, p. 36-37), consistente, coerente, enquadrador, equilibrado, extensível, integrador, relevante e com a potencialidade de proporcionar a transferência/utilização de saberes em situações novas (PACHECO et al., 2009).

Em relação aos objetivos que o novo currículo deve perseguir, o documento ressalva que ao $3^{\circ}$ ciclo do ensino básico compete proporcionar o desenvolvimento sistemático e diferenciado

\section{[...] da cultura moderna, nas suas dimensões, teórica e prática, hu- manística, literária, científica e tecnológica, artística, física e des- portiva, necessária ao prosseguimento de estudos ou à inserção na vida activa, bem como a orientação vocacional escolar e profissio- nal, que proporcione opções conscientes de formação subsequen- te $[\ldots .$.$] , no respeito pela realização autónoma da pessoa humana.$ (PACHECO et al., 2009, p. 38)}

O plano salienta que esses objetivos devem ser, por sua vez, operacionalizados sob três vias: formações transdisciplinares; componentes curriculares; e componentes não curriculares.

Em relação às formações transdisciplinares, o plano menciona que se trata das "línguas oficiais timorenses - Tétum e Português -, da educação para a paz, da utilização das tecnologias de informação e comunicação e da dimensão humana do trabalho, bem como da integração de Timor-Leste no espaço asiático" (PACHECO et al., 2009, p. 38), a serem abordadas em todos os anos e em todas as áreas e disciplinas. Acrescenta que tais formações não contemplam um programa

\section{0}

Prescrição curricular é ressalvada no documento como "um conjunto

de princípios sobre as áreas curriculares e as disciplinas, os conteúdos programáticos, as orientações metodológicas, os materiais curriculares e a avaliação, para além da definição de um conjunto de princípios de desenvolvimento do currículo" (PACHECO et al., 2009, p. 34). 
específico, mas requerem a disposição permanente dos professores para a sua concretização.

Em relação à componente curricular, é ressaltado que esta deve integrar "as diferentes disciplinas, organizadas por áreas curriculares de desenvolvimento, enquanto a componente não curricular, de natureza facultativa, diz respeito às actividades que concorrem para o enriquecimento do currículo" (PACHECO et al., 2009, p. 38). Nessa medida, segundo diretrizes do plano, a componente curricular deve integrar três áreas e respetivos temas/disciplinas em função das aprendizagens que os alunos devem concretizar e das capacidades, competências gerais e específicas, procedimentos, atitudes e valores que devem desenvolver ao longo do $3^{\circ}$ ciclo, designadamente, nas áreas de:

- desenvolvimento linguístico - Tétum, Português, Inglês;

- desenvolvimento científico - História e Geografia, Matemática, Ciências da Natureza;

- desenvolvimento pessoal e social - Educação Artística, Educação Física, Educação Religiosa e Moral, Educação para a Cidadania e os Direitos Humanos (PACHECO et al., 2009).

Para cada uma das componentes, o plano define um conjunto de finalidades específicas. No que se refere ao desenvolvimento linguístico, o documento sugere que essa área deve

\begin{abstract}
[...] proporcionar aos alunos um conjunto de experiências de aprendizagem que, tomando como objecto línguas com um diferente estatuto político, cultural, educativo e social, assegure as oportunidades, as atitudes e a vontade de desenvolvimento dos saberes linguísticos necessários à realização dos objectivos de vida de cada um, ao enriquecimento pessoal, à participação no mundo do trabalho e ao envolvimento informado na vida comunitária. (PACHECO et al., 2009, p. 38)
\end{abstract}

Nessa medida, o plano ressalva, desde logo, um currículo que se oriente para o desenvolvimento de "valores da herança cultural, em particular [em relação às] [...] diferentes línguas e tradições, [...] [e] valores orientadores do tipo de sociedade que se pretende construir" (PACHECO et al., 2009, p. 5).

Para a área de desenvolvimento científico, o documento destaca uma componente curricular que vise a

[...] dotar os alunos de saberes culturais, científicos e tecnológicos que os tornem aptos a compreender aspectos da realidade e a lidar adequadamente com situações problemáticas que se Ihes coloquem enquanto cidadãos. As aquisições que assim se pretende 
garantir são também aquisições de linguagens especializadas, próprias dos diferentes domínios em que se organiza o conhecimento humano. (PACHECO et al., 2009, p. 39)

Em relação à área de desenvolvimento pessoal e social, o documento releva um currículo que promova

[...] a aquisição de saberes (conhecimentos, capacidades e atitudes) que contribuam para a consolidação da identidade nacional, para o desenvolvimento de valores como a solidariedade, o respeito pelos outros, a compreensão perante diferença, que desenvolvam o sentido ético perante a vida e o trabalho, que garantam uma relação harmoniosa com o corpo e que promovam as potencialidades de expressão estética de cada um. (PACHECO et al., 2009, p. 39)

Em suma, englobando três áreas curriculares, o plano do EPS valoriza a aquisição e o desenvolvimento de

[...] saberes, valores, atitudes, procedimentos e capacidades em diferentes áreas do saber [...] [e, em particular, foca-se na] formação pessoal e social, [justificando este foco ao salientar que o perfil de formação que se pretende] não pode ser dissociado da realidade timorense e sobretudo do papel que a escola deve desempenhar na valorização de atitudes e valores colectivos e da preparação para a vida profissional e em comunidade. (PACHECO et al., 2009, p. 40)

Fundamentando-se na LBE, o plano entronca em três grandes eixos, ou em três orientações curriculares fundamentais: relevância cultural; desenvolvimento humano integrado; e aprendizagem centrada no aluno (PACHECO et al., 2009). Expressa que "estas orientações devem estar presentes em todo o processo de desenvolvimento do currículo, que se assume como um currículo baseado em competências, seja competências gerais seja competências específicas” (PACHECO et al., 2009, p. 42). Nesse contexto, o documento propõe que a matriz curricular a partir da qual serão elaborados os programas inclua orientações metodológicas adequadas a uma organização curricular centrada na aprendizagem dos alunos. Enfatiza ainda que a nível de programas haja "adequação das metodologias de ensino aos objectivos e natureza das aprendizagens e às características dos conteúdos” (PACHECO et al., 2009, p. 44).

Em relação às práticas avaliativas, o documento destaca as avaliações 
e que corresponde à elaboração e aplicação de testes; formativa a implementar de forma sistemática e contínua de modo que o aluno possa superar dificuldades e melhorar as suas aprendizagens. (PACHECO et al., 2009, p. 82)

No entanto, o plano realça que "no ensino básico a avaliação tem uma função de orientação e formação, pelo que a modalidade principal é a avaliação formativa” (PACHECO et al., 2009, p. 44). Salienta ainda que, numa planificação de aula, o professor deve recorrer a "actividades de avaliação mais informais e facilmente operacionalizadas, o que não significa dizer que não deva basear-se em registos, de modo a ter uma noção mais clara sobre o que os alunos aprendem, ou não, e sobre o que é necessário fazer ao longo da aula, ou das unidades didácticas" (PACHECO et al., 2009, p. 65).

Numa outra dimensão, o documento alerta para a coerência curricular a que devem obedecer os programas, designadamente, ao nível da

[...] adequação dos conteúdos aos alunos, entendidos tanto no seu contexto sociocultural, como na sua idade e níveis de desenvolvimento cognitivo, com base no reconhecimento da gradualidade das aprendizagens; [...] [da] ordenação dos conteúdos, tendo em conta o grau de complexidade e abstracção das aprendizagens; [...] [da] articulação vertical dos conteúdos, isto é, à sequência dos conteúdos das diversas áreas e disciplinas em função dos anos de escolaridade; [...] [da] articulação horizontal dos conteúdos, ou seja, à integração das aprendizagens a partir do contributo das áreas e disciplinas num determinado ano de escolaridade [...] [e da] extensão e profundidade na abordagem dos conteúdos, em função do nível de ensino e do ano de escolaridade. (PACHECO et al., 2009, p. 43-44)

Todos esses aspetos são considerados pertinentes quando se está perante o desenho e implementação de um novo currículo.

Focando-nos, em particular, na articulação vertical entre os currículos de dois níveis educativos consecutivos, como é o caso do EPS e ESG em Timor-Leste, discute-se, a seguir, a relação entre os referidos currículos.

\section{RELAÇÃO ENTRE OS CURRÍCULOS DO ENSINO PRÉ-SECUNDÁRIO E SECUNDÁRIO GERAL EM TIMOR-LESTE}

Muitos estudos reconhecem que reformas do currículo do EPS tiveram grande impacto no acesso e desempenho dos alunos ao ensino secundário (MUNAVU; OGUTU; WASANGA, 2008). Para que essa transição seja coroada de sucesso, é necessário que a mesma seja feita sem sobressaltos (GIMENO SACRISTÁN, 1996). Para isso, muito contribui a 
articulação que possa existir, quer a nível teórico, quer prático, entre os referidos currículos. De facto, assegurando-se uma adequada articulação teórica e prática entre currículos de dois níveis educacionais consecutivos, existirão certamente menores retenção e/ou abandono escolar e haverá melhor desempenho dos alunos no nível de ensino posterior e, consequentemente, progressão dos seus estudos.

Em Timor-Leste, tal como em muitos países, o $3^{\circ}$ ciclo, pela sua natureza terminal do ensino básico, representa a transição para o ensino secundário (PACHECO et al., 2009). Nesse panorama educativo, pode-se evidenciar um conjunto de articulações verticais e horizontais envolvendo o EPS e o ESG (Figura 1).

\section{FIGURA 1 \\ REPRESENTAÇÃO ESQUEMÁTICA DE ARTICULAÇÕES VERTICAIS E HORIZONTAIS ENTRE OS NÍVEIS DE ESTUDOS EM TIMOR-LESTE}

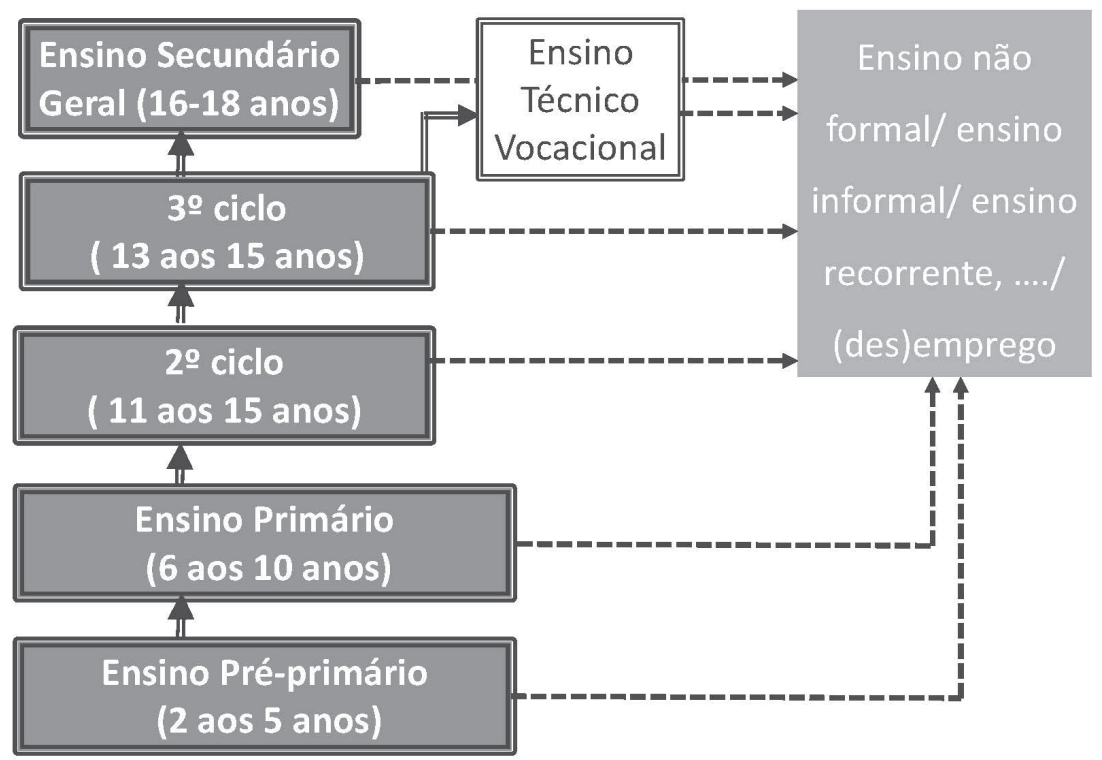

Fonte: Elaboração das autoras.

Esquematicamente, na Figura 1, as setas horizontais representam a articulação nessa direção, que pode ser resultante da retenção dos alunos no ano anterior, do abandono escolar dos alunos que não se qualificam para a transição vertical, ou mesmo do prosseguimento de estudos por outra via, como o ensino técnico vocacional ou ensino recorrente. As setas verticais permitem evidenciar as articulações nessa direção que se estabelecem entre níveis educacionais consecutivos, em que as transições de um nível para outro são determinadas pelo desempenho do nível anterior.

Ao nível do EPS, o Plano curricular do $3^{\circ}$ ciclo do ensino básico e estratégia de implementação expressa claramente, como se viu no ponto anterior, o interesse e a necessidade de existir tal articulação vertical (PACHECO et al., 2009). 
No que concerne ao Plano curricular do ensino secundário geral (TIMOR-LESTE, 2011c), defendem-se e de forma clara expõem-se, em secção própria, as articulações privilegiadas entre o currículo do ESG e o do $3^{\circ}$ ciclo/EPS. Tal plano destaca, principalmente, que a sua estrutura/desenho funciona como uma continuação natural do $3^{\circ}$ ciclo, ao qual pretende dar sequência, “consolidando competências já adquiridas e estimulando uma autonomia progressiva dos alunos” (TIMOR-LESTE, 2011c, p. 21). Acrescenta-se, como o próprio plano do EPS subscreve, que a

\section{[...] articulação entre o 3ํ Ciclo e o Ensino Secundário Geral realiza- -se quer em termos de áreas de formação existentes no 3 Ciclo, às quais procura dar seguimento e aprofundamento, quer ao nível de disciplinas que no Ensino Secundário representam já uma certa especialização. (TIMOR-LESTE, 2011c, p. 21)}

Assim, a articulação teórica entre os dois planos perspetiva-se, desde logo, na continuidade que existe a nível das mesmas áreas curriculares: linguísticas, científicas e pessoal e social, ao nível da consolidação de saberes cada vez mais especializados e na melhoria do indivíduo e da sua cultura, na promoção da sua responsabilidade social e da sua autonomia.

Veja-se, mais especificamente, se tal articulação encontra ressonâncias relativamente a dimensões mais particulares dos currículos.

Ao nível dos princípios enquadradores, verifica-se que ambos os planos curriculares estão assentes em documentos de abrangência nacional (e.g. Lei de Bases da Educação, Programa do IV governo constitucional). No entanto, o plano do ESG apoia-se em outros documentos de abrangência internacional, como os relacionados com a Década da Educação para o Desenvolvimento Sustentável - DEDS -, a Educação para Todos - EPT -, a Década da Literacia - DL - e as Metas de Desenvolvimento do Milénio - MDM. Defende, assim, princípios que se prendem, nomeadamente, com uma educação para o desenvolvimento sustentável - EDS -, em geral, e para melhoria da qualidade de vida (uma das finalidades da EDS), redução da pobreza (uma das metas das MDM), a equidade (outra das metas das MDM e da EPT), a democracia (uma das metas da EDS) e promoção de competências de pensamento crítico e de resolução de problemas (metas da DEDS e DL), em particular. Tais princípios vão, portanto, na senda dos enunciados no plano do ESP, designadamente os que se prendem com o desenvolvimento sustentável, a promoção da paz e da estabilidade social, a educação para a cidadania, a realização e responsabilização pessoal e social, o combate do insucesso, do abandono e do absentismo, a inclusão de crianças e adolescentes com necessidades educativas especiais e a resolução de problemas e desafios os mais variados. E numa lógica de envolvimento de toda a comunidade 
e de transdisciplinaridade, entendida como um meio de compreender melhor e aprofundar a integração de Timor-Leste no seu contexto geopolítico (PACHECO et al., 2009; TIMOR-LESTE, 2011c).

Em relação aos objetivos gerais, parece aqui ser evidente uma articulação entre os dois planos, dado que o currículo do ESG persegue os objetivos definidos para o EPS numa perspetiva de continuidade entre ciclos, de consolidação de competências, de desenvolvimento de capacidades acrescidas (e.g. de reflexão e de raciocínio no ESG), privilegiando a oferta de percursos distintos que permitam quer o prosseguimento de estudos, quer a inserção na vida ativa. Em relação à componente curricular, tanto o plano do EPS quanto o do ESG distinguem como principais objetivos a perseguir o desenvolvimento de literacias e de competências transversais e específicas no âmbito das várias áreas curriculares. Em particular, ambos privilegiam o desenvolvimento de competências linguísticas, comunicativas e digitais que permitam a participação de todos na sociedade, o desenvolvimento da capacidade de reflexão, raciocínio, espírito crítico e respeito pela diversidade, a construção de uma perspetiva sobre o mundo que respeite a diversidade social, cultural e linguística, a valorização do conhecimento científico na compreensão de problemas locais e globais, a valorização do conhecimento na sua resolução, mitigação e no desenvolvimento económico, social e ambiental da sociedade e, por último, a promoção do exercício de cidadania numa perspetiva de responsabilidade partilhada.

Relativamente aos temas/conteúdos, o plano do ESG preconiza, como já referido anteriormente, uma continuidade com o do EPS ao nível das componentes curriculares. Em relação à área do desenvolvimento linguístico, é mencionado no plano do ESG que as disciplinas de Tétum, Português e Inglês se mantêm, acrescentando-se o Indonésio. Em relação à língua portuguesa (TIMOR-LESTE, 2011c), este plano reforça a ideia, tal como o plano do EPS, de se manter sua relevância. Tal língua não só é vista como uma forma de comunicação, mas também como um veículo cultural e artístico que importa desenvolver (CABRITA et al., 2015).

$\mathrm{Na}$ área do desenvolvimento científico, o plano do ESG (TIMOR-LESTE, 2011c) realça que as disciplinas, Matemática e Ciências Físico-Naturais do $3^{\circ}$ ciclo se desdobram em Matemática, Física, Química, Biologia e Geologia, numa perspetiva de especialização e aprofundamento de saberes "compatíveis com a filosofia do Ensino Secundário e com a possibilidade de continuação de estudos superiores” (TIMOR-LESTE, 2011c, p. 21). O mesmo ocorre em relação à componente de Ciências Sociais e Humanidades, uma vez que a disciplina de História e Geografia do $3^{\circ}$ ciclo “dá lugar a duas disciplinas distintas, História e Geografia”, às quais vão se juntar “a Sociologia, a Economia e Métodos Quantitativos e os Temas de Literatura e Cultura, permitindo um enriquecimento e uma diversificação considerável das competências e das referências dos alunos” 
(TIMOR-LESTE, 2011c, p. 21). Esse plano esclarece que a disciplina de Matemática existente no $3^{\circ}$ ciclo, no caso da componente das Ciências e Tecnologias no ESG, continua como disciplina de Matemática e, no caso da componente de Ciências Sociais e Humanidades, continua como disciplina de Economia e Métodos Quantitativos (TIMOR-LESTE, 2011c).

Por sua vez, na área do desenvolvimento pessoal, o plano do ESG reconhece que se mantêm

\footnotetext{
[...] as preocupações já presentes no 3 Ciclo em disciplinas como Educação Cívica, Cidadania e Direitos Humanos ou em Competências para a Vida e para o Trabalho, agora mais específicas em Cidadania e Desenvolvimento Social ou, para alguns alunos, também presentes nos programas de Sociologia e, transversalmente, em muitas outras. (TIMOR-LESTE, 2011c, p. 22)
}

No entanto, o plano do ESG vai mais além, ao propor a exploração de temas específicos como os relacionados com as MDM e de EDS no âmbito da Componente de Ciências e Tecnologias, e de temas relacionados com a valorização dos recursos naturais, o combate à pobreza e à exclusão social, a defesa dos direitos humanos e o envolvimento dos alunos com a realidade do mundo e com a compreensão de fenómenos globais no âmbito da Componente de Ciências sociais e Humanidades. Isso não impede que sua abordagem não seja efetuada em articulação e continuidade com a abordagem de temas realizada no EPS, para cada uma das áreas (linguística, científica e pessoal e social).

Ao nível de orientações metodológicas, o currículo do ESG preconiza também uma aprendizagem centrada no aluno, orientada para ação e o reconhecimento, pelos alunos, das potencialidades dos saberes a construir. Realmente, o plano do ESG segue uma perspetiva construtivista da aprendizagem e um ensino de cariz exploratório, o que vem na continuidade do EPS, sem descurar a adequação de metodologias de ensino e de aprendizagem aos objetivos e natureza das aprendizagens e às caraterísticas dos conteúdos (PACHECO et al., 2009).

Ao nível da avaliação, o plano curricular do ESG realça como modalidade principal a avaliação formativa, em continuidade ao proposto no plano curricular do EPS, numa perspetiva de orientação e formação sem, por isso, desprestigiar outras formas de avaliação.

\section{CONCLUSÕES}

O alargamento da escolaridade obrigatória requer maior atenção aos momentos de transição dos alunos dentro de um sistema de ensino. Tal aspeto coloca novos desafios à escola e aos docentes, visando à continuidade dentro do mesmo sistema, o que implica uma maior articulação 
entre os diferentes níveis de ensino. Dado o papel que a articulação entre os currículos de dois níveis educativos consecutivos assume em contexto de reforma curricular, na presente comunicação abordou-se a articulação vertical que existe entre os currículos do EPS e ESG em Timor-Leste. Para tanto, analisaram-se os planos curriculares de cada um dos níveis de estudo em termos de princípios, objetivos, temas, orientações metodológicas e avaliação.

Reconheceu-se uma articulação vertical entre os currículos, ao nível da continuidade não só das áreas curriculares, bem como dos objetivos, orientações metodológicas e avaliação. Em relação às áreas curriculares, denotou-se uma continuidade ao nível do comum reconhecimento da importância da consolidação e aprofundamento dos saberes disciplinares, da promoção da língua portuguesa e da promoção da realização e responsabilização pessoal, social e cultural do indivíduo.

Assim, o modo como os currículos foram construídos propiciará certamente aos alunos timorenses que deles fizerem uso, atualmente, a continuidade e o aprofundamento de saberes, bem como a construção de uma visão global dos conhecimentos, quando eles transitarem do EPS para o ESG.

Para que essa articulação seja mais profícua é necessário, contudo, o trabalho colaborativo entre os professores, o que implica diálogo e reflexão entre as várias partes envolvidas no processo de ensino e aprendizagem. Implica, ainda, que não só os planos curriculares estejam articulados verticalmente entre si, mas também que essa articulação exista e seja profícua ao nível dos outros materiais curriculares, como ao nível dos programas curriculares/programas escolares, manuais do aluno, guias do professor. Importa ainda que cada professor tenha a capacidade de mudar, reestruturar, relacionar, interligar, sintetizar e conhecer (LIMA, 2012). Espera-se, assim, que estes profissionais timorenses adotem e partilhem este caminho e, da melhor forma, operacionalizem as articulações existentes entre o Plano curricular do $3^{\circ}$ ciclo do ensino básico e estratégia de implementação e o Plano curricular do ensino secundário geral, visando a garantir aos seus alunos o aprofundamento de saberes, com vista à progressão nos estudos e/ou integração na vida ativa, e uma efetiva integração, responsabilização e participação sociais.

\section{REFERÊNCIAS}

ALARCÃO, I. A educação das crianças dos 0 aos 12 anos. In: SEMINÁRIO EDUCAÇ̃̃O DAS CRIANÇAS DOS 0 AOS 12 ANOS, 20 de maio de 2008, Lisboa. Actas.... Lisboa: Conselho Nacional de Educação, 2009. (Estudos e relatórios).

BARBOSA, E. J. M. M. Articulação curricular e (in)sucesso educativo na disciplina de inglês: um estudo exploratório. 2010. 187 f. Dissertação (Mestrado em Ciências da Educação, Área de Especialização em Desenvolvimento Curricular) - Instituto de Educação, Universidade do Minho, Braga, 2010. 
BAKER, J. Evaluating the impact of development projects on poverty: a handbook for practitioners. Washington DC: The World Bank, 2000.

CABRITA, I.; LUCAS, M.; CAPELO, A.; FERREIRA, A.; SANTOS, C.; MORGADO, M.; BREDA, Z. Ensino secundário geral em Timor-Leste: perspetivando o futuro. Aveiro: Universidade de Aveiro Editora, 2015.

CAPELO, A.; CABRITA, I. Cooperação internacional para a construção da qualidade educativa: avaliação a médio prazo da implementação da restruturação curricular do ensino secundário em Timor-Leste. Indagatio Didactica, v. 7, n. 2, p. 128-143, 2015.

FERREIRA, J. B. Continuidades e descontinuidades no ensino básico. Leiria: Magno, 2001.

FONTOURA, M. O currículo na gestão e organização das escolas. In: COSTA J. A.; MENDES, A. N.; VENTURA, A. (Org.). Liderança e estratégia nas organizações escolares. Aveiro: Universidade de Aveiro Editora, 2000. p. 249-267.

GABRIELSON, C.; SOARES, T.; XIMENES, A. Assessment of the state of science education in Timor Leste. 2010. Disponível em: ‘http://competence-program.asia/wp-content/uploads/2012/03/Assessmentof-the-State-of-Science-Education-in-Timor-Leste.pdf . Acesso em: dez. 2015.

GERTLER, P.; MARTINEZ, S.; PREMAND, P.; RAWLINGS, L.; VERMEERSCH, C. Impact evaluation in practice. Washington D.C.: The World Bank, 2011.

GIMENO SACRISTÁN, J. La transición a la educación secundaria: discontinuidades en la cultura escolar. Madrid: Morata, 1996.

INSTITUTO NACIONAL DE FORMAÇÃO DE DOCENTES E PROFISSIONAIS DA EDUCAÇÃO. Projeto de Formação Inicial e Contínua de Professores. 2014. Disponível em: <http://www.pficp-esgestv.com/>. Acesso em: dez. 2015.

LIMA, M. S. A. F. A articulação curricular no ensino básico no âmbito da disciplina de inglês. 2012. 89 f. Dissertação (Mestrado em Ciências da Educação Especialização em Administração e Organização Escolar) - Universidade Católica Portuguesa, Porto, 2012.

MULLER, J. On the shoulders of giants: verticality of knowledge and the school curriculum. In: MOORE, R.; ARNOT, M.; BECK, J.; DANIELS, H. (Org.). Knowledge power and educational reform: applying the sociology of Basil Bernstein. London: Routledge, 2006. p. 11-27.

MUNAVU, R. M.; OGUTU, D. M.; WASANGA, P. M. Sustainable articulation pathways and linkages between upper secondary and higher education in Africa. In: ASSOCIATION FOR THE DEVELOPMENT OF EDUCATION IN AFRICA (Org.). Biennale on education in Africa: beyond primary education: challenges and approaches to expanding learning opportunities in Africa. Maputo: ADEA, 2008. (Working document - draft).

NDEBELE, N.; BADSHA, N.; FIGAJI, B.; GEVERS, W.; PITYANA, B.; SCOTT I. A proposal for undergraduate curriculum reform in South Africa: the case for a flexible curriculum structure. Report of the Task Team on Undergraduate Curriculum Structure. Pretoria: Council on Higher Education, 2013 (Discussion document).

PACHECO, J.; MORGADO, J.; FLORES, M. A.; CASTRO, R. Plano curricular do $3^{\circ}$ ciclo do ensino básico e estratégia de implementação. Braga: Universidade do Minho, 2009. Disponível em: 〈http://repositorium.sdum.uminho.pt/handle/1822/10402〉. Acesso em: 12 dez. 2015.

RIBEIRO, A. S. A escola pode esperar: textos de intervenção sobre a educação de infância. Porto: Asa, 2002.

ROLDÃO, M. C. Que educação queremos para a infância? In: ALARCÃO, I. (Coord.). A educação das crianças dos 0 aos 12 anos. Lisboa: Conselho Nacional de Educação, 2009. p. 198-220.

SERRA, C. Currículo na educação pré-escolar e articulação curricular com o $1^{\circ}$ ciclo do ensino básico. Porto: Porto, 2004.

SHAH, R. Goodbye conflict, hello development? Curriculum reform in Timor-Leste. International Journal of Educational Development, v. 32, n. 1, p. 31-38, 2012.

STABBACK, P.; MALE, B.; GEORGESCU, D. What makes a good quality school curriculum? Geneva: United Nations Education, Scientific and Cultural Organization-International Bureau of Education, 2011. (Background paper). 
TIMOR-LESTE. Ministério da Educação. Política Nacional da Educação 2007-2012. Díli: Ministério da Educação, 2007.

TIMOR-LESTE. Ministério da Educação. Plano Estratégico de Desenvolvimento 2011-2030. Díli: Ministério da Educação, 2011a.

TIMOR-LESTE. Ministério da Educação. Plano Estratégico Nacional da Educação 2011-2030. Díli: Ministério da Educação, 2011b.

TIMOR-LESTE. Ministério da Educação. Plano Curricular do Ensino Secundário Geral. Díli: Ministério da Educação, 2011c.

TIMOR-LESTE. Ministério da Educação. Política Nacional da Educação e da Cultura 2006-2010. Díli: Ministério da Educação, 2006. Disponível em: «http://www.jornal.gov.tl/lawsTL/RDTL-Law/RDTLGov-Resolutions-P/Gov-Res-2007-03.pdf). Acesso em: 12 jan. 2015.

TIMOR-LESTE. Ministério da Educação. Education for All 2015 National Review Report: Timor-Leste. Dili: Unesco, 2015.

UNITED NATIONS EDUCATIONAL, SCIENTIFIC AND CULTURAL ORGANIZATION. Youth and skills: putting education to work. Paris: Unesco, 2012. (EFA global monitoring report 2012).

UNITED NATIONS CHILDREN'S FUND. Evaluation Office. Evaluation of the UNICEF Education Programme in Timor Leste 2003-2009. New York: Unicef, 2010.

UNITED NATIONS CHILDREN'S FUND. Termos de Referência (TDR) para Contrato Institucional. Díli: Unicef, 2008.

\section{ANA MARGARIDA CAPELO}

Centro de Investigação em Didática e Tecnologia na Formação de Formadores

- CIDTFF -, Universidade de Aveiro, Aveiro, Portugal

anacapelo@ua.pt

ISABEL CABRITA

Centro de Investigação em Didática e Tecnologia na Formação de Formadores - CIDTFF -, Departamento de Educação e Psicologia, Universidade de Aveiro, Aveiro, Portugal

icabrita@ua.pt 